\title{
INTRODUCING DECONSTRUCTIVE INTERSECTIONALITY: THE GENERAL JURISPRUDENTIAL RAGE AGAINST RAINBOW THEORY
}

\author{
by Tamryn Gorman*
}

\section{Introduction}

Despite South Africa's post-modern constitutional dispensation ${ }^{1}$ which, at first glance, seems to celebrate and entrench substantive equality - various judgements have been passed by the Constitutional Court where the Constitution was interpreted through a formal equalitarian lens. ${ }^{2}$

On the one hand, substantive equality recognises and celebrates our diversity and differences whereas formal equality, on the other hand, obsesses with the idea of sameness. ${ }^{3}$ This constant tension between substantive and formal equality is aptly portrayed by the term 'rainbow jurisprudence'. ${ }^{4}$ This term was coined by Alfred Cockrell to explain a quasi-theory depicted by the newly born South African constitutional adjudication which was lacking in substantive reasoning (which I equate to substantive equality) and the absence of a rigorous jurisprudence. ${ }^{5} \mathrm{He}$ goes so far as to assimilate the finding of genuine substantive reasoning within these judgements to the possibility of touching a rainbow - a mythical task which, although alluring, seems impossible. ${ }^{6}$ Thus, I have identified the problem that South Africa is still submerged in rainbow jurisprudence. This can be seen through various court cases that will be discussed below, ranging from cases that were clearly decided from a formal equalitarian perspective to those which depict a wolf in sheep's clothing -

* Third year LLB student at the University of Pretoria.

1 K Klare 'Legal culture and transformative constitutionalism' (1998) 14 South African Journal on Human Rights 150 - 151

2 The Constitution of the Republic of South Africa $1996 \mathrm{sec} 9$; Prince $v$ President Cape Law Society 2002 (2) SA 391 (CC); Jordan and Others v S 2002 (6) SA 642 (CC).

3 A Smith 'Equality constitutional adjudication of South Africa' (2014) 2 African Human Rights Law Journal 609 - 632.

4 A Cockrell 'Rainbow jurisprudence' (1996) 12 South African Journal of Human Rights 11.

5 Cockrell (n 4 above) 11.

6 As above. 
seemingly substantive judgements disguising the formal equality lurking beneath. ${ }^{7}$

In order to prove the survival of this rainbow jurisprudence, I will discuss, in the first part of this essay, how modernism has influenced the perpetuation of rainbow jurisprudence and the negative effects that this has had on the law. More specifically, I will rely on positivism and liberalism as two branches of modernist theories to explore their contribution to the idea of sameness, as well as the connection between these jurisprudential perspectives and formal equality, resulting in a restricted jurisprudence.

In the second part of this essay, I will contrast the modernist legal culture - that is littered with rainbow jurisprudence and damaged by formal equality as described above - to substantive equality and a post-liberal reading of the Constitution. ${ }^{8}$ I will argue that substantive equality aims to eradicate formal equality: the latter perpetuating systemic inequality through the ideal of sameness which is presented by both positivism and liberalism, the former ensuring that laws do not re-inforce the subordination of classes/ groups who were already suffering by accommodating their differences. ${ }^{9}$ The approach of favouring substantive equality will highlight that subordination and deprivation still exists today and has survived because of our reception of legal positivism, as well as through our liberal reconciliatory practices due to the injustices of Apartheid. ${ }^{10}$

I will provide a two part solution to the problem of rainbow jurisprudence and the ideal of achieving substantive equality in the third part, through what I call, 'deconstructive intersectionality'. 11 This term incorporates both a critical realist perspective based on Jacques Derrida and John Dugard, as well as the notion of intersectionality from the second wave feminists. This solution will be applied specifically to judges for various reasons discussed below. I will further rely on Magistrate Van Der Ligt from Ettiene Van Heerden's Ancestral Voices, resembling (but different from) Dworkin's Hercules J, as the model judge. Lastly, I will discuss how this two part solution will allow South Africa to move towards a general jurisprudence.

7 See for example Prince v President, Cape Law Society 2002 (2) SA 391 (CC); Jordan and Others v S 2002 (6) SA 642 (CC); Minister of Home Affairs and Another v Fourie and Another/Gay and Lesbian Equality Project and 18 Others v S 2002 (6) SA 642 (CC).

8 Klare (n 1 above) 151-156.

9 H Botha 'Equality, plurality and structural power' (2009) 25 South African Journal on Human Rights 4.

10 Botha (n 9 above) 4

11 Botha (n 9 above); $\mathrm{G}$ Minda Post-modern legal thought: Law and jurisprudence at century's end (1995) 117. 


\section{The contributions of a modernist legal culture towards rainbow jurisprudence, formal equality and restricted jurisprudence.}

In this part of this essay I aim to show that modernist legal culture is the vehicle driving rainbow jurisprudence and formal equality which results in a restricted jurisprudence. In order to do this, I aim to link modernism to state-centeredness and the resultant approach of positivism. Secondly, I attempt to connect modernism with liberalism and its individualist claims to sameness. Finally I relate the above two traits of modern theory to the application of formal equality, perpetuation of rainbow jurisprudence and the resultant restricted jurisprudence.

Modernism depicts an era in legal theory that is a result of the power of the sovereign being absolute. ${ }^{12}$ During the later developments in Natural Law thinking, the primacy of God's will as depicted through the voluntarism as per Ockham was replaced by De Groot and the primacy of Man's will. ${ }^{13}$ This was eventually replaced by the superiority of the State's power which was created through the sacrifice of part of man's freedom according to Hobbes and Locke. ${ }^{14}$ These theories depict natural law shifts in terms of which the will of the sovereign is at the centre of the enquiry and through this, the state obtains absolute power. ${ }^{15}$ This change in thinking resulted in the birth of liberalism and therefore, modernism as well. ${ }^{16}$ Veitch supports this through his opinion that modernism, as a dominant legal understanding, regarded law as a body of rules stemming from the State as the single source of law. ${ }^{17}$

The above shift in thinking to absolute power of the sovereign links to Bentham's positivist ideal of utilitarian command, which argues that the State, as the sovereign, is not a creature of the law, but rather the creator thereof. ${ }^{18}$ Therefore, the State is superior and has to be obeyed without question. ${ }^{19}$ Moreover, it relies on the strict separation of law and morality which separated all non-law from law, resulting in a purer version of the law with a strict reliance on rules and principles. ${ }^{20}$ This brand of positivism was the dominant legal

W Le Roux 'Natural law theories' in C Roederer \& D Moelendorff (eds) Jurisprudence (2004) 46

13 Le Roux (n 12 above) 39-41.

14 Le Roux (n 12 above) 41-46.

15 Le Roux (n 12 above) 42

16 Le Roux (n 12 above) 46.

17 S Veitch Jurisprudence: Themes and concepts (2nd ed) (2007) 248.

8 Veitch (n 17 above) 248.

19 Le Roux (n 12 above) 42

20 C Douzinas \& A Geary Critical jurisprudence: The political philosophy of justice (2005) 4 . 
theory in England in the 18th century and was brought to South Africa through the British annexation of the Cape in 1806. ${ }^{21}$

Even today, over two centuries later, this legal tradition is especially observed in its purest form in the court room where judges interpret the law through a strict adherence to the rigid distinction between the branches of government - a characteristic intrinsic to Bentham's command theory - as well as upholding a firm distinction between law and morality. 22 Thus, the judiciary's rejection of legal values is seemingly justified through its allegedly mechanical approach in finding the intention of Parliament. ${ }^{23}$

The positivistic rejection of legal values and strict separation between law and morality led to an allegedly apolitical reading of the Constitution whereby one objective and rational standard was applied to everyone.

Above, I have shown the link between modernism, statecenteredness and the approach of positivism. I will now attempt to connect modern theory with liberalism and its individual claims to sameness.

Modernism is also generally portrayed through another shift in natural law through the challenge of law based on the individual claims to subjective rights carved in the inner conscience of all human beings as opposed to the basis of external legal relationships. ${ }^{24}$ This is supported by Locke who argued that every human has subjective rights - such as life, liberty and property - and that the State needs to respect these rights. ${ }^{25}$ Therefore, this is the start of the liberal theory where Locke's idea of subjective rights ultimately led to the formation of constitutional rights. Furthermore, according to Veitch, the three distinct characteristics of modernism are: 'the law being at the centre for the constitution of political power, regulating economic transactions and governing social life. 26 These characteristics of modernity are said to mirror the arguments of liberals. ${ }^{27}$

The main objective of a Liberal bill of rights is to secure the liberty and property of a person from imposition by the State. ${ }^{28}$ In addition to this, a liberal constitution is largely individualistic, accommodates very few socio-economic rights, places few

21 J Dugard 'The judicial process, positivism and civil liberty' (1971) 88 South African Law Journal 184

22 C Albertyn \& D Davis 'Legal realism, transformation and the legacy of Dugard' (2010) South African Journal of Human Rights 188-216.

23 Dugard (n 21 above) 187.

24 Le Roux (n 12 above) 27.

25 Le Roux (n 12 above) 43.

26 Veitch (n 17 above) 264.

27 As above.

28 Klare (n 1 above) 153. 
affirmative duties on the government, is highly protective of private property, is mostly vertical in its application and lacks a caring/ communitarian ethos. ${ }^{29}$ Through this it can be seen that liberalism discards the objective good for the promotion and protection of subjective rights. ${ }^{30}$ The modern idea of rights is that they are subjective domains of absolute power, thus once again the notion that they cannot be questioned. ${ }^{31}$

Liberals define existence as an individual matter of free will. ${ }^{32}$ Thus, they would accentuate the race, class, gender and sex neutrality of their efforts - as well as the neutrality of the law that serves them - in order to emphasise the purpose of their movement being that of equality with the state of the oppressor. ${ }^{33}$ However, this neutrality of the law and the liberal movement risked essentialising humanity, meaning that one person's experiences were equated to the experience of another, irrespective of aspects such as class, age, race and sexual orientation. ${ }^{34}$ Hence, Douzinas argues that this is too simplistic and doesn't accommodate other areas of life, such as race, gender, sexual orientation and religion. ${ }^{35}$ Such simplistic characterisation of others based on a single group/class formulates grand theories that become stereotypical in their thinking that all women or all black people are in the same class, thus their experiences are identical. ${ }^{36}$ Through this, liberalism denies the values of community and human relationships by their universal perspective that prioritised the values of autonomy and self-interest only. ${ }^{37}$

Moreover, liberalism utilises a simplistic approach of opposing individual rights with public interest. Through this concentration on human rights, liberalism has reduced humans to walking rights - mere objects to hold the absolute power of these rights and nothing more. ${ }^{38}$ This, coupled with the view that the subjective rights are automatically inscribed in all individuals - irrespective of the sovereign, allowed liberal theory to mask subjective choices in the law as these rights. ${ }^{39}$

As I have shown above, positivism flourishes in South Africa because of our adherence to a conservative legal culture. Secondly, with the introduction of our bill of rights we see a rise in liberal legal theory in the context of the introduction of rights to all people. The

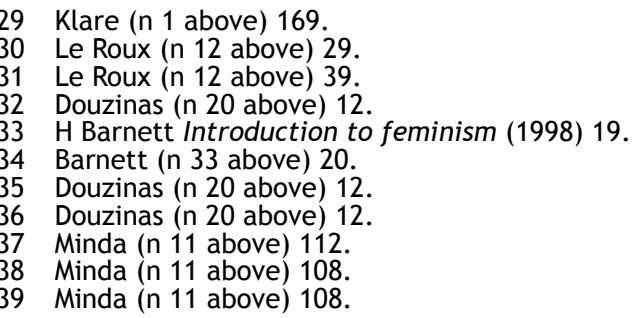


two together shows the perpetual existence of modernist thought in South Africa today. As a result of this, lawyers were trained to apply the law mechanically and to never question what the law ought to be but rather to blindly accept the law as it is. ${ }^{40}$ Hence, modernism is seen as the 'norm' and is the mainstream thinking of the majority of lawyers in South Africa. ${ }^{41}$

The law is extremely exclusionary if it is applied from one dominant perspective. ${ }^{42}$ I have shown so far that the current legal culture of South Africa is typically positivistic. Furthermore, this positivism is supplemented by liberalism which perceives itself as a mere extension of traditional theory and not an alternative theory altogether. ${ }^{43}$ Thus, both elements of positivism and liberalism are incorporated into modernism as the traditional legal culture within South Africa that is the current dominant perspective and is responsible for exclusionary methods - as will be argued in the proceeding paragraphs.

Modernism viewed all rational law to be the height of progress for humanity. ${ }^{44}$ This is supported by Douzinas who states that law and reason are fundamental to modernity. ${ }^{45}$ Law today emphasises the divide between law and politics by providing for rational processes that allow lawyers to arrive at determinate legal outcomes by basing this process on supposedly neutrally phrased rules and principles. ${ }^{46}$ Through positivism and liberalism, the law has pretended to be objective, rational and neutral. ${ }^{47}$ However, beneath this façade of detached neutrality, law is actually permeating with inarticulate premises, male-centric norms and white supremacy. ${ }^{48}$

South Africa's unique history of colonisation, Apartheid and patriarchy portrays vast material and structural inequality and subordination. ${ }^{49}$ If colonisation introduced positivism - a theory which I have argued above is still the dominant jurisprudence in South Africa today - and the attempts of liberals to reconcile the injustices of the past which has resulted in the recognition of comfortable difference and grand theorising, is it possible then that this structure of the law, which is neutral and objective at face value - is still perpetuating structural inequality? $?^{50}$

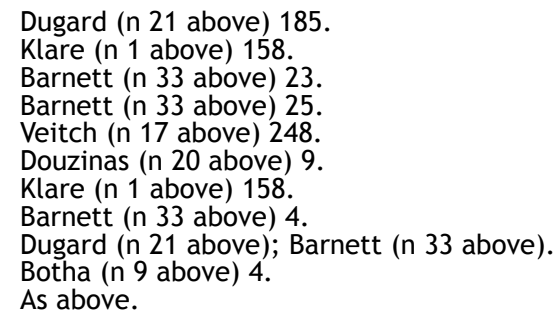


An important issue that arises from a discussion of inequality is discrimination. Section 9 of the Constitution filters complaints regarding alleged discrimination through broad group-based classes such as race, gender, sex or sexual orientation. ${ }^{51}$ This seems to suggest that differences among individuals can be reduced to these basic social categories. This is a complacent understanding of difference based on a universal principle which grandly theorises group-based distinctions stating that the identities and experiences of all blacks or all women or all homosexuals are the same. ${ }^{52}$ Not only does this categorisation of individuals into one specific group or class reject this important history of all other classes, but it also fails to acknowledge that discrimination can overlap and intersect over various classes and groups. ${ }^{53}$ Therefore, it may be found that a black woman who alleges discrimination constitutes fair discrimination based on race, however, this discrimination may be unfair in terms of sex. Through this we can see how positivism's reliance on strict rules and principles and liberalism's fight to bring different people to the same level is unreceptive to true differences. ${ }^{54}$

Rather, this structure of the law acknowledges comfortable differences founded on broad group/class based categories which actually assimilate, for example, the experiences of a black heterosexual man as well as a black homosexual man as the same because they are both black, or both men - depending on the group based discrimination that is being alleged. 55 This shows how the recognition of this comfortable difference has actually equated difference with sameness. ${ }^{56}$ These class/ group based categories that humans are divided into represent the perspectives of the middleclass westernised elite based on their experiences. ${ }^{57}$ Thus, these class/group based categories have been merged through the perspectives of these middle-class westernised elite who have been schooled in positivism ever since the colonisation, who represent the liberal views that all people must be equal regardless of their circumstances and have particularly male-centric norms. ${ }^{58}$

This means that these group based classifications have to comply with the conventions of this norm as set by this westernised, middleclass elite. Therefore, the law has become reductionist in these simplistic categorisations as well as exclusionary through the use of

51 Botha (n 9 above) 2.

52 Botha (n 9 above) 5 .

53 Botha (n 9 above) 5 - 6.

54 Botha (n 9 above) 6

55 As above.

56 Botha (n 9 above) 18.

57 As above.

58 As above. 
conventional understandings and norms based on the dominant approach of modernism. ${ }^{59}$ Through the essentialism, reductionism and exclusionary nature of law, the freedom of individuals to make their own decisions is non-existent as their decisions are already circumscribed for them based on these group/ class based categories. ${ }^{60}$ As a result of this, a gap is created between the law and the materiality of human life through the failure of the law to address individual needs by the objective approach that the law follows. ${ }^{61}$

In light of the above, both branches of modernity have failed to acknowledge the complexities of human existence. Moreover, through the single objective standard incorporated by positivism and the stereotypical grand theorising of liberalism, it can be argued that both perspectives assimilate difference to sameness. This assimilation of different people being treated the same is achieved through the use of formal equality as will be argued below.

Formal equality is a form of interpretation with the belief that all persons in the same situation should be treated exactly the same, irrespective of other aspects such as race, religion, sex, gender etc which are seen as arbitrary. ${ }^{62}$ Through this it can be seen that formal equality has a deep obsession with sameness as it equates the experiences of one person belonging to a specific group based on a specific class as the same as all the others of that class. Thus, although formal equality differentiates between dichotomies - such as black/white, male/female - formal equality actually assimilates these differences to sameness by the blatant attempt to ignore all other intersecting aspects of human life. ${ }^{63}$ Through this, systemic inequality is perpetuated whereby, for example, the previously disadvantaged black men are classified as simply men or black women are grouped as simply black. Such simple dichotomies ignore the existence of human life, the social being and feed into laws which aid in the survival of the subordination of such people.

This formal equality can be expressed as the dominant form of legal interpretation through its obsession with sameness. Formal equality is a product of modernity as the dominant legal culture through the strict reliance on the pure law of positivism and the essentialism of liberal theory which both aid in the objective and rational standards of modernism as explored above.

This has perpetuated the survival of rainbow jurisprudence which describe the tactics used by judges to beguile the eyes of the reader

Botha (n 9 above) 6.

60 Botha (n 9 above) 8.

61 Botha (n 9 above) 6.

62 Smith (n 3 above) 610

63 Prince v President, Cape Law Society 2002 (2) SA 391 (CC); Jordan and Others v S 2002 (6) SA 642 (CC). 
with flashy judgements and magical wording in order to distract us from the actual lack of substantive equality as envisaged by the Constitution in order to conceal the formal equalitarian interpretation that was relied on due to our modern legal culture. ${ }^{64}$ This commitment to mainstream thinking in line with formal equality and modernism has contributed to the impoverishment of law into a body of principles and rules that are void of any values, meaning, morality and substance, thus the law has been reduced to a restricted jurisprudence. ${ }^{65}$

Thus, a chasm exists between the traditional approach of the courts (reflecting positivism and liberalism) and the transformative constitutionalism envisaged by the Constitution. ${ }^{66}$ Therefore, the only antidote for the illness that is rainbow jurisprudence is a pure, radical reliance on substantive equality.

\section{Substantive Equality}

Previously it was shown how positivism, and liberalism by extension, prefers an apolitical and liberal reading of the Constitution. However, under the 'new' constitutional dispensation, we have a duty to challenge the modern legal culture that we are faced with as well as the interpretive practices that accompany it. ${ }^{67}$ If the current legal culture is damaged by modernism, then I argue that a post-modern theory is the next logical approach to reach constitutional transformation. A post-modern theory denies the sorting of individuals into class/ group based categories, thus it rejects the obsession with sameness caused by formal equality, positivism and liberalism. ${ }^{68}$ Furthermore, it acknowledges the differences between individuals as well as their differing circumstances by recognising that each individual has various characteristics that all intersect with one another such as a race, sex, religion, gender, sexual orientation. ${ }^{69}$

For the reasons mentioned above, I argue in favour of Klare's postliberal reading of the Constitution. ${ }^{70}$ The reasons for this are that, in contrast to a liberal constitution, the Constitution of the Republic of South Africa supports a collective self-determination as well as an individual self-determination. ${ }^{71}$ This can be seen through the inclusion of positive duties on the State which has a social, redistributive and caring ethos. ${ }^{72}$ Thus it can be argued that the South

64 Klare (n 1 above) 156

65 Douzinas (n 20 above) 10.

66 Klare (n 1 above) 170.

67 Klare (n 1 above) 168.

68 Barnett (n 33 above) 8 .

69 Barnett (n 33 above) 9.

70 Klare (n 1 above) 150.

71 Klare (n 1 above) 153.

72 Klare (n 1 above) 153. 
African Constitution portrays a departure from liberalism. ${ }^{73}$ The Constitution is said to recognise diversity, celebrate uBuntu, emphasise the need to reconcile the injustices caused under Apartheid, identify the need for self-realisation and be self-conscious of our history. ${ }^{74}$ Furthermore, the Constitution visualises an equality that can exist in the space of the world and not just within the law a substantive rather than a formal equality. ${ }^{75}$ This can be seen through section 9 of the Constitution which entrenches substantive equality in order to exterminate and remedy the influence of the group based disadvantage mentioned above. ${ }^{76}$ Through this the Constitution can be both the potential for power as well as the agent for legal reform within South Africa. ${ }^{77}$ However, the Constitution is not self-executing and the interpretation of the Constitution is what holds the power to humanise or to dehumanise the world. ${ }^{78}$ The more accommodating interpretation of the Constitution - being through substantive equality, which will be explained further below - would lead to a post-modern identity in terms of which the law can become more self-conscious and reflective, which is in line with the postliberal reading of the Constitution. ${ }^{.79}$

According to Barnett, the law needs to be placed in its wider context as it does not exist in a vacuum. ${ }^{80}$ From this it follows that the concrete life experiences of the people who are regulated by the law must be considered when dealing with the law. ${ }^{81}$ In order to do this, we need to dismantle the systemic inequality of the law by recognising the diversity of the people of South Africa. ${ }^{82}$ In order to do this, people need to challenge the majority beliefs in positivism and liberalism as well as the practice of formal equality. ${ }^{83}$

The law is not a set of rules but rather a form of life. ${ }^{84}$ Therefore, the law should claim meanings from experience and make that meaning real. ${ }^{85}$ In order to make experiences mean something, the law must recognise the complexity of human experience in that the social beings who have these lived experiences cannot be reduced to separate autonomous regions such as merely race, merely class,

73 Klare (n 1 above) 152.

$74 \mathrm{~L}$ Du Plessis 'The South African constitution as monument and memorial and the commemoration of the dead' in R Christensen \& P Bobo (eds) Rechtstheorie in rechtspraktischer Absicht (2008) 191-192; Klare (n 7 above) 154-155.

75 Klare (n 1 above) 154.

76 Botha (n 9 above) 4.

77 Barnett (n 33 above) 11.

78 J Boyd White 'Justice in tension: an expression of law and the legal mind' (2012) 9 No Foundations 18.

79 Minda (n 11 above) 125-126.

80 Barnett (n 33 above) 23.

81 Botha ( $\mathrm{n} 9$ above) 10.

82 Barnett (n 33 above) 21.

83 Botha (n 9 above) 15

84 Boyd White (n 78 above) 1.

85 Boyd White (n 78 above) 5 . 
merely sex, merely gender etc. ${ }^{86}$ These bases of existence are not closed and non-negotiable, but are rather the crossroads that creates experiences where they meet and intersect. ${ }^{87}$ In order for the law to recognise this complexity of human life, the Constitution needs to be interpreted through substantive equality.

Substantive equality treats individuals as substantive equals. ${ }^{88}$ This means that the law realises that not all people are 'on the same playing field' and therefore, ensures that it does not perpetuate the subordination of groups who have already suffered from some form of disadvantage. ${ }^{89}$ Moreover, substantive equality recognises the importance of social beings and the intersections between their race, sex, class, gender and sexual orientation. ${ }^{90}$ Through this, substantive equality celebrates diversity and difference. ${ }^{91}$

Thus substantive equality rejects grand theorising and is tailored to the needs of individuals by recognising the complexity of social life. ${ }^{92}$ Through this, the law can accommodate diversity, the variability of humans in South Africa and be open to radical difference. ${ }^{93}$ This radical difference treats humans as ends in themselves and not as mere bodies of walking rights or objects of bureaucratic power. ${ }^{94}$ This destabilises the dichotomies of objective and subjective or black and white or male and female that the modern legal culture relies so heavily on. ${ }^{95}$ The possibilities under substantive equality would be infinite as opposed to the grand theories which aim to limit and assimilate. ${ }^{96}$ This will allow the people to reimagine the world we live in and create new identities for ourselves as opposed to those fixed on us by the middle-class, westernised elite. ${ }^{97}$ Through this, every human being will once again be responsible for his/ her own choices. ${ }^{98}$ Moreover, this celebration of difference brings together both the community as well as the self by constantly being moulded and shaped through the relationships we have with others and not on fixed, objective criteria. ${ }^{99}$ A progressive legal culture such as this commitment to substantive equality is necessary for the long term successful constitutional transformation in order to create

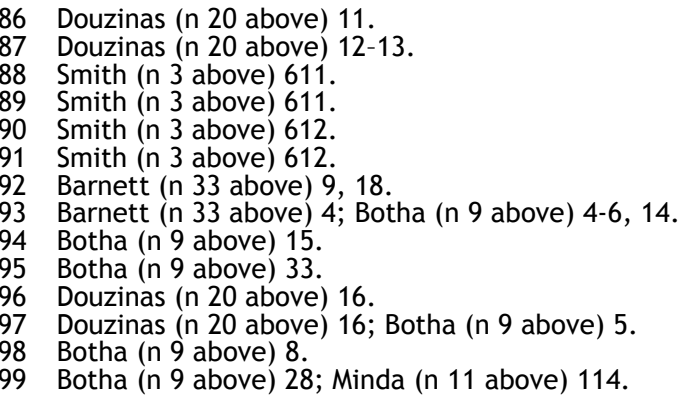


power in the community and allow people to have a capacity for selfdetermination outside of seemingly neutral dichotomies.

Therefore, 'a rigorous engagement for substantive [equality] will ... make us aware of constitutional colours that we never even dreamed of ... under our fixation of rainbow jurisprudence - not just green and blue, but emerald, jade, azure, turquoise and aqua'. ${ }^{10}$

However, once again, the Constitution is not self-executing. The drafters of the Constitution could not have perceived that the wide phrases (in order to accommodate change in a changing society) would be interpreted with positivism and formal liberalism as habits of mind. ${ }^{102}$ Therefore, we need a new, radical approach to adjudication in order to move towards constitutional transformation. ${ }^{103}$

\section{Deconstructive intersectionality and Magistrate Van der Ligt}

Although the judiciary are not the only ones to blame for this rainbow jurisprudence - there appears to be a mentality of formal equality among the population as well - I have chosen the judiciary as a focal point for this essay for various reasons which will now be discussed. Our legal imagination has been constricted by hierarchies created through modernism, therefore, we balk at any mention of adjudicative transformation. ${ }^{104}$ This is seen as an uncomfortable way of thinking because it goes against the mainstream norm of preservation of judicial sterility when interpreting statutes. ${ }^{105}$ Therefore, the constant use of bizarre and unusual theories will push against the conventional understandings which will then allow space for transformation. ${ }^{106}$

Judges represent the moment that the abstract principles of the law meet the world and they represent an intersection of all aspects of life. ${ }^{107}$ Therefore, the courts need to use substantive equality in order recognise radical difference and diversity within the law, however, they rely on positivism and liberalism to eradicate choice and power within their judgements that this causes an objective and formal equalitarian approach to interpretation. ${ }^{108}$

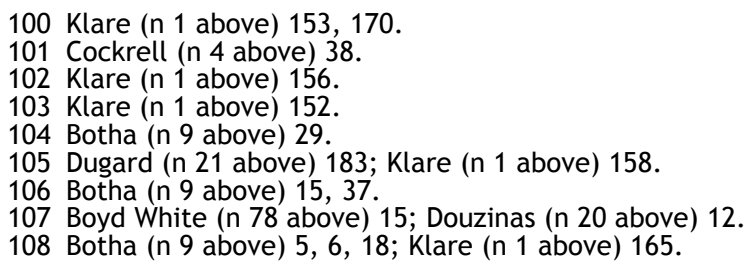


Thus, we cannot move towards constitutional transformation through substantive equality without rethinking the manner in which the judiciary approaches interpretation. ${ }^{109}$ Moreover, the Constitution encourages self-reflection regarding legal methods, specifically with regard to the judiciary. ${ }^{110}$ The judiciary is not criticised by many legal academics (once again a result of our legal culture) however, 'the absence of criticism does not promote infallibility, it merely encourages the belief therein'. ${ }^{111}$ Lastly, a slightly more obvious reason being that there is little point in schooling future lawyers about substantive equality if they are to end up fighting a claim in the court room in front of a judge who is institutionally biased and formulates his/ her judgements through the application of positivist techniques. ${ }^{112}$

If we accept for a moment that I am correct in saying that the above is sufficient reasoning to centre this essay on the judiciary, then it makes sense to proceed on with a discussion of how the judiciary interpret statutes based on our legal culture of rainbow jurisprudence and modernity.

The Constitution is phrased widely in order for it to be interpreted in light of the changes in society. Therefore, there are gaps and ambiguities in the Constitution that judges are required to interpret and fill. ${ }^{113}$ Interpretation is a meaning creating activity and judges need to work within the law as the material through which this meaning needs to meet the world. ${ }^{114}$ Thus, especially in constitutional adjudication, it cannot be denied that value judgements need to be made, relying on extra-legal concepts. ${ }^{115}$

Through the arguments of lawyers and inherent flexibility of legal materials through interpretation, cases represent an opportunity to open the law up to endless possibilities by providing the judiciary with a wide discretion. ${ }^{116}$ This creates tension within judges because their discretion introduces moral and political influences. ${ }^{117}$ These tensions cannot be resolved by mere recollection of and reliance on pure rules and principles, but rather by an art of using one's mind and interpreting languages, representing a set of possibilities, giving life to the law. ${ }^{18}$ However, the judiciary downplay these influences and

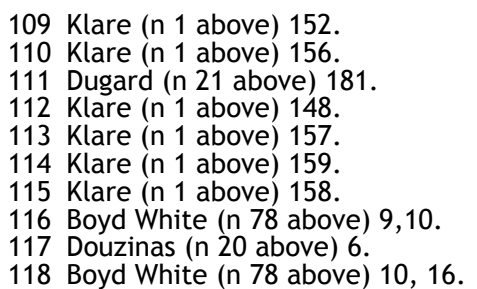


tensions by a strict adherence to their alleged mechanical approach in merely finding the intention of the legislatures. ${ }^{119}$

Dugard argues that judges are also subjected to human limitations, such as their likes, dislikes, race, class gender, sex, sexual orientation etc as these are all aspects that shape human experience, mould their perspectives and create their identities; these are cultural imperatives which shape the human being. ${ }^{120}$ These cultural imperatives also establish inarticulate premises which subconsciously influence the judgements handed down by the judiciary. ${ }^{121}$ Although positivism has attempted to make the judiciary insusceptible to value judgements and act purely mechanically, it cannot remove these inarticulate premises. ${ }^{122}$ Positivism merely denies that these premises exist (which allows them to flourish) thereby concealing them behind seemingly objective and neutral laws. ${ }^{123}$ However, by denying their existence, positivism is only encouraging the existence of subliminal forces that influence judges through their institutional bias to the modern legal culture. ${ }^{124}$ This merely undermines the transparency of the law. ${ }^{125}$

As a solution to the above, Dugard emphasises that judges need to acknowledge that they are influenced by these inarticulate premises. ${ }^{126}$ However, how is this to be accomplished through a judiciary so heavily reliant on hiding behind positivism and denial?

The first step in my two part solution introduces a critical realist perspective of a feminist concept, what I call 'deconstructive intersectionality. ${ }^{, 127}$

The term intersectionality is a feminist notion which means that a person is not just one isolated class/group based category, but rather a multiple-way crossing in terms of which all aspects of life, such as race, sex, gender, sexual orientation and religion meet. ${ }^{128}$ These various aspects of life are cultural imperatives which orient our perspectives regarding how we see the world, rights from wrong, shape our identity, likes and dislikes and determine who we are, what we see and how we see it. ${ }^{129}$ Therefore, if judges can acknowledge this intersectionality existing within themselves, then they would be more accommodating to recognise this intersectionality of the claimants whose fate lies in their hands. Through this, radical

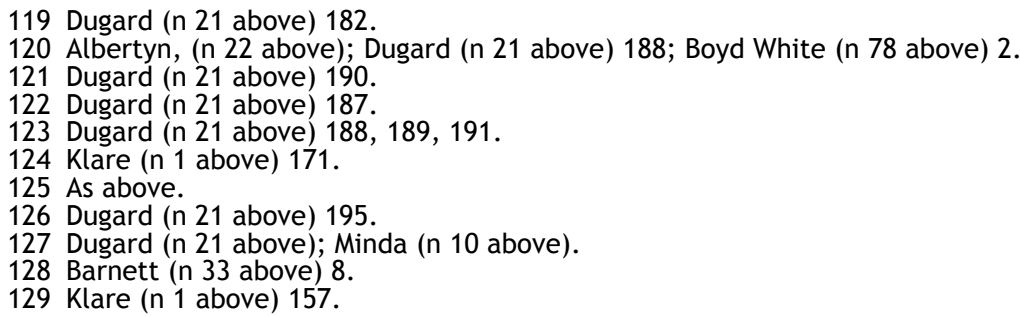


differences will be celebrated, systemic inequality will be properly addressed and interpretation can occur through substantive equality. ${ }^{130}$

Du Plessis argues that there are two approaches to constitutionalism, namely memorial and monumental. ${ }^{31} \mathrm{~A}$ memorial approach is conscious of its limits and looks at the past while a monumental approach celebrates life and achievements. ${ }^{132}$ In order for judges to fully commit to this acknowledgement of their own intersectionality and transformative constitutionalism, they need to accept their own personal memory as memorial while simultaneously monumentalising the memory of the people on trial by using the personal experiences of the judges based on their class, race, sex, gender and sexual orientation to constantly allow them to be aware of the possibility of a slip of their impartiality into potential bias and disadvantage based on the intersectionality of the person sitting in front of them. ${ }^{133}$ By this I mean that instead of celebrating their personal influences through judgements that perpetuate systemic inequality due to their particular experiences, they need to memorialise this memory as well in order to allow these inarticulate premises to warn them of the potential that their judgement could be unfairly decided based on these cultural predispositions. By so doing, these judges will be able to identify the memorial memory of the person sitting in front of them as a victim of subordination through systemic inequality perpetuated by class/ group based distinctions. Once this has been identified, the judge can monumentalise this memory (being that of the person on trial) through commemorating the past injustices but allowing the person to be seen as a substantive equal who can celebrate their radical difference based on their individual aspects of life such as race, gender, class etc. ${ }^{134}$

This intersectionality is described as deconstructive. This description follows the formation thereof by Derrida, a critical legal scholar, who argues that deconstruction challenges the law to reshape our dominant legal culture by reversing the hierarchies that modernity has caused in order to affirm elements of human life through the affirmation of the complexity of human existence and rejection of essentialism. ${ }^{135}$

The aim of this deconstructive intersectionality is therefore to abandon the positivistic divide between law and morality and to reject the essentialism of the liberalist movement by acting as a portmodern solution in terms of which judges can acknowledge that they

130 Smith (n 3 above) 631

131 Du Plessis (n 74 above) 189.

132 As above.

133 As above.

134 As above.

135 Minda (n 11 above) 114, 118, 120. 
are influenced by subliminal forces and use this acknowledgment to eradicate systemic inequality and celebrate radical difference, a movement towards substantive equality.

This recognition of intersectionality to play a deconstructive role will allow the law to be more truthful with itself and allow judges to make value laden decisions and accept their moral responsibility in the choices that follow. ${ }^{136}$ This will be more in step with a post-liberal reading of the Constitution. ${ }^{137}$

An example of a model judge who embraces a deconstructively intersectional approach, akin but not identical to Dworkin's Hercules $\mathrm{J}$, is that of Magistrate Van de Ligt from Ettiene van Heerden's novel Ancestral Voices. ${ }^{138}$ Upon reading about the travels of the Magistrate on the train to Toorberg, I was reminded of the strong positivism of the South African judges through his memorisation of abstract papers of neat drawings of blood lines instead of an actual experience of physical relationships of human beings who actually exist in the reality of the novel. ${ }^{139}$ Moreover, the Magistrate was obsessed with pre-determined questions that constituted a rational process in terms of which he would be able to extract one determinate legal answer from the general principles of clinical guilt - the one person who was clearly guilty of the murder of the young deceased. ${ }^{40}$ However, as the novel progresses, Magistrate van der Ligt quickly realises that the black letter of the law that he has practiced in for so many years is not sufficient and does not apply in this context where the abstract rules of the law are failing to adhere to the social problems when these rules meet with the real world. Eventually, through a metamorphosis, the Magistrate acknowledges that his personal influences have become involved in his investigation of the mysterious death of the young Trickle Du Pisani, completely against his will, but through this he was able to realise that there was more to the world than the basic concepts of the legal culture he found himself in. As a result, he acknowledged the full life of Ella Moolman (through her history, sex, race, gender and all other parts of her intertwined existence) and admired her for this. Hence, Magistrate Van der Ligt accepted his inarticulate premise of loving Ella Moolman as the monumental reincarnation of his deceased wife and that this ultimately would have had a subconscious influence on his decision about the guilt of the Moolmans in Trickle's death. In order to memorialise this, in the last letter that the Magistrate wrote to his deceased wife, it seems as though he could not find Abel Moolman guilty in such a basic sense of the word that the law circumscribed.

136 Klare (n 1 above) 164, 165.

137 Klare (n 1 above) 165

138 E van Heerden Ancestral voices (2011). [page number for reference]

139 Van Heerden (n 138 above). [page number for reference]

140 Van Heerden (n 138 above). [page number for reference] 
The second step in my two step solution relies on Dugard's argument that once judges can accept that they are influenced by inarticulate premises, then they will be more accustomed to be influenced by accepted legal values. ${ }^{141}$ In Dugard's argument, these values are those found in common law. ${ }^{142}$ However, it is my contention that the accepted legal values that judges would be more accommodating of in the new constitutional dispensation is those entrenched in the Constitution, specifically substantive equality and uBuntu. ${ }^{143}$

Although it is difficult to define, uBuntu has been described as a philosophy of life. ${ }^{144}$ The values of uBuntu include humanity, respect, personhood, human dignity, compassion and morality. ${ }^{145}$ uBuntu is specifically important in this context as it used to describe the potential of a human being due to the fact it differentiates, not only between comfortable dichotomies such as man and woman, but also between radical differences in the varying gradations of the essence of those individuals, this is a progressive African concept of substantive equality. ${ }^{146}$ Moreover, the inclusion of this philosophy of life into the law will enhance the ability of any jurisprudence to move towards a transformative constitutionalism by recognising the vast networks of human existence that can be found within the South African dispensation. ${ }^{147}$

It is my argument that deconstructive intersectionality, as I have defined it in the previous section, will pave the way for the courts to consider the circumstances of people as substantive equals. This means that the law will reflect a plurality of voices, needs, races, religions, cultures, interests, sexes, genders and classes, not only creating the capacity for plurality in the self, but also in the community. ${ }^{148}$ Through this, various aspects of the individual as well as the complexity of human life will continue to be recognised on a case by case basis which will allow for the recognition of the possibilities of life in law. ${ }^{149}$ Thus, social being and social existence will form part of the law. ${ }^{150}$ Substantive equality will allow extralegal considerations to loom large in the 'new' jurisprudence that South Africa finds itself in, which will include aspects such as economics, politics, sociology, psychology etc merged with the law in order to create a platform that will knot human experiences together

141 Dugard (n 21 above) 195.

142 As above.

143 S v Makwanyane and Another 1995 (3) SA 391 (CC).

144 Y Mokgoro 'uBuntu and the law in South Africa' in D Cornell \& N Mavangua (eds) uBuntu and the law: African ideals and post-apartheid jurisprudence (2012) 317. 145 Mokgoro (n 144 above) 317.

146 Mokgoro (n 144 above) 318

147 Mokgoro (n 144 above) 319

148 Boyd White (n 78 above) 14; Botha (n 9 above) 5.

149 Boyd White (n 78 above) 16

150 Douzinas (n 20 above) 10. 
in order to 'attach the body to the soul and bind it to the broader community' as a representation of social being. ${ }^{151}$ This being is always becoming in endless relationships with others as a 'communism of the heart'. ${ }^{152}$ This is the essence of a general jurisprudence; it is the joint reconstruction of social life, humanity and the law in order to deconstruct bureaucratic power structures and the harsh and unjust application of mere rules, principles and essentialist, universal stand points. ${ }^{153}$

\section{Conclusion}

I have argued that the current legal culture of South Africa is damaged by modernism, plagued by positivism, littered with liberalism and stuck in rainbow jurisprudence which has contributed to a formal equality perspective on interpretation and a restricted jurisprudence. I have argued that this has perpetuated systemic inequality through group/class based categories that have resulted from formal equality's obsession with sameness. Furthermore, in order to counter this problem, I have shown that a post-liberal reading of the Constitution which supports substantive equalitarian interpretation is a more accommodating approach in light of South African transformative constitutionalism. The two part solution that I envisaged in order to reach this transformation is the introduction of a feminist concept in light of a critical realist perspective, namely the acknowledgement of what I call 'deconstructive intersectionality' by the judiciary. The second step in my solution is that after the acceptance of this deconstructive intersectionality, judges can be more accommodating of accepted legal values such as constitutional values and uBuntu. Furthermore, I made use of Magistrate Van der Ligt in Ettiene van Heerden's novel Ancestral Voices as the model judge. Lastly I described how this movement from rainbow jurisprudence to substantive equality through deconstructive intersectionality would create a pathway for general jurisprudence. After all, without a shift towards substantive equality and the influence of general jurisprudence, positivism and liberalism aid in the perpetuation of inequality through simple dichotomies of life that fail to unearth radical differences while obsessing with sameness, resulting in a 'law [which] is at best a corpse and at worse, a zombie'.154

151 Douzinas (n 20 above) 1, 13.

152 Douzinas (n 20 above) 16.

153 Minda (n 11 above) 120.

154 Douzinas (n 20 above) 18. 